\title{
IFRS 17 contractual service: a life insurance perspective
}

[Institute and Faculty of Actuaries, Sessional Event, 5 October 2020, Webinar only]

The Moderator (Ms O. N. Gaughan, F.I.A.): This is a sessional event run by the Institute and Faculty of Actuaries (IFoA) on the topic of the "IFRS 17 Contractual Service Margin: a Life Insurance Perspective".

The panel members are Wijdan Yousuf (Aon - UK); Natalia Mirin (Mazars - UK); Brendon Thorpe (Discovery Life - South Africa); Joanna Stansfield (Lloyds Banking Group - UK); Kruti Malde (ICICI Prudential Life - India); Rob Walton (PwC - UK); and Leong Tan (Swiss Re Australia).

I am Olive Gaughan (Mazars - Ireland). I have been a member of the IFoA since 1990, and I feel privileged to have been invited to preside over this event today. I have been involved in IFRS 17 for a few years now and have been involved with a number of panels, both asking questions and answering questions.

The working party was set up in the summer of 2018 (around a year after IFRS 17 was first published) with work being undertaken in the context of a period where the standard had not bedded down. Indeed, it is only in recent months that we have a final version of the standard, but work had to begin as we knew what most of it was going to look like. The working party came together to analyse the standard, look at methodologies to think about what actuaries need to know, to think about it from a technical perspective, and produce some papers to benefit all of us.

The working party has produced a lot of content so far, particularly LinkedIn articles. The culmination of all those efforts is today's sessional paper.

Mr W. Yousuf, F.I.A. (introducing the paper): The paper is primarily about the Contractual Service Margin (CSM), as the title suggests. In the paper, we are looking at what IFRS 17 asks us to do. Then we consider what implications those requirements have in terms of the finer technical details, the commercial impacts, the operational aspects, and so forth.

The way we have approached topics depends on what the issue is that we are discussing. For example, when looking at something like contract boundaries, we found it most sensible to compare IFRS 17 requirements with those of Solvency II. At times, when we look at discussions in relation to loss components, for example, what we think is most sensible is to explain what results will look like if loss component requirements did not exist. At other times, we simply compare how the requirements that seem suitable in certain jurisdictions possibly do not make much sense in other jurisdictions. A very good example of that is the appropriateness of allowing for the time value of money in coverage unit measurements.

The paper is primarily intended for life actuaries who are familiar with IFRS 17, but that said, we are fairly comfortable that the material can be readily engaged with by people with less familiarity with the requirements. We have done this by spending a bit of time in the paper going through some of the basic concepts, and providing some context to the background to the problems that we have discussed, wherever possible. 
Obviously, we need to recognise that the paper cannot cover every conceivable problem that a particular company might face. As we know, there are issues that affect some companies and countries more than others. While we hope that experienced practitioners might be able to refer to this paper to validate their own conclusions or pick new points of detail, there will naturally be some topics that the paper is silent on and does not cover at all.

The paper itself has seven sections and the order of the sections is designed to correspond to the order in which they appear in the actual standard. So, for example, we have the level of aggregation and recognition appearing first, followed by measurement, followed by transition, etc.

By far, the greatest amount of material relates to the measurement section that covers several of the more technical topics, for example, VFA eligibility; assessment of contract boundaries; the determination of coverage units; challenges that reinsurance contracts have, particularly because of the 2019 amendments; and some of the issues in the with-profits space. We have allocated some material to transition, in particular, the challenges and considerations that companies could face. We touch a bit on areas of interest across KPIs and management information, specifically what might happen now that we have this peculiar thing called the CSM on the balance sheet.

Regarding conclusions, unlike many other sessional papers, for example, Solvency II risk margin working party ones, because of the nature of IFRS 17, we do not have any tangible or straightforward conclusions. We do not say whether IFRS 17 as a whole is sensible or not.

Instead, we are drawing attention to the fact that there are a number of different ways that insurers could go about interpreting or applying the standard, and often arguments that have been advanced in favour of a particular point of view are likely to have just as strong a counterargument against it. Ultimately, where companies will eventually land will depend on how they look at their particular problems and the wider business and commercial environment in which they are operating.

Having Brendon (Thorpe), Leong (Tan), and Kruti (Malde) as non-UK panel members has been extremely useful as part of the working party to widen our own understanding in the UK of how problems are being perceived.

Our conclusion is that lots of judgements are needed in applying IFRS 17 and this means that it will take time for users, preparers, and all other stakeholders to start understanding what these numbers mean and how they can use that information once it starts to emerge.

For a number of the topics that we have discussed in the paper, we have added links to secondary sources and other materials that we think would be useful for readers to be able to supplement their understanding.

In addition, we also have a section in the further reading appendix that provides links to material available from other groups. In particular, we have added a number of papers from the Canadian Institute of Actuaries who have produced some great material across a number of different topics, as well as links to some of our sister working parties, specifically the IFRS 17 Discount Rates Working Party.

The Moderator: I think we can launch into the panel discussion. The standard is now final. We are on the home straight, and insurers are looking at an implementation date that is now set in stone and working towards delivering on that. I will go to Jo (Stansfield) for this one. What do you see as the biggest outstanding IFRS 17 CSM challenges for entities?

Mrs J. R. Stansfield, F.I.A.: For me, the challenge is that while we have this final standard, there is still a huge amount of uncertainty out there in terms of how some areas should be interpreted. As a result, it is difficult for entities to tie down their methodologies. Without that final methodology, the projects that are building IFRS 17, and having to deliver it, are still running a little bit blind or at best they are at significant risk of there being late changes to their build requirements. 
I think that I would pull out three areas where there is still the most uncertainty. First, there is the area of coverage units, how we release the CSM to the P\&L. That uncertainty is caused by the high level of judgement needed. There have been late changes to the standard around coverage units, meaning that the goalposts have moved a little bit. Also, it is a hugely commercially material area. Therefore, it really matters to people, and that means that it is an area where everybody is struggling.

Second, probably a more niche one, but with-profits still has lots of uncertainty surrounding it. A lot of that is due to the nature of with-profits. I think the ring-fenced funds and the pooling of risk really cause challenges. IFRS 17 has been designed as an international standard to apply to all insurance business across the entire globe. Inevitably, some of those more unusual products are going to struggle to fit into that more generic approach.

Last, but by no means least, is the area of transition. Again, this is hugely material and an enormous amount of judgement is needed.

The other big general challenge we have is the operationalising of IFRS 17. A lot of focus has been spent on debating some of the finer technical details about the interpretations, and exactly what the right way of doing things is. Fundamentally, while we have this exact detail of what we should be doing, if we cannot build that in a way that allows us to calculate our monthly accounts according to the working day timetable that is required by our company, then it does not really help us.

For me, there must be a real balance and engagement between the technical areas developing the methodology, and the operational areas, so that we understand the challenges as we proceed rather than the challenges jumping up to bite us at the end.

The Moderator: We are now proceeding into the four areas of the panel discussion. The discussion will cover transition, reinsurance, coverage units, and with-profits.

We are going to begin with questions on transition. The first question on this topic: what are the biggest problems for life insurers in the retrospective application of the standard at transition?

Mr R. Walton, F.I.A.: I think the default approach under IFRS 17 of full retrospective application is a particular challenge for life insurers, particularly those who have large in-force books and often a mix of legacy systems in place as well.

For older blocks of business, applying the standard retrospectively clearly requires a lot of data, assumptions and models from a long time ago. It is quite often the case that those do not exist anymore or there might be a lot of effort needed to try to source those. I think that the standard allows for the fact it is not always going to be possible to do this. It is why there is an assessment of impracticability there in terms of whether you can apply the standard retrospectively or not, and it is why the options exist for modified retrospective or fair value approaches.

I do not think that anyone should see either of those approaches as the easy options though. I think that each of these brings its own challenges. The modified approach needs careful assessment of the modifications that are available. You need to demonstrate impracticability for each of those. You are limited to those that are specified in the standard. Not all of them are going to be suitable for all types of business.

Fair value, on the other hand, might solve some of the challenges around the availability of data. But it brings its own challenges in terms of setting a methodology and calibrating it.

I guess that the biggest problem that I would highlight is that when we say retrospective application, we mean applying your accounting policy and prior periods without the use of hindsight. Most insurers have not finalised their IFRS 17 accounting policy yet and being able to demonstrate objectively how you would have applied that in historic periods is, I believe, a huge challenge.

I know that one of the examples that I have come across is on risk adjustment. You set your accounting policy on risk adjustment that will in turn help determine your initial CSM. How do 
you point to an historic view of risk that aligns with your proposed accounting policy going forward and objectively do that in prior periods without any hindsight?

The point of retrospective application without hindsight is to me a big issue that insurers and their auditors are going to need to work through.

The Moderator: What is the range of options available on the comparability of life insurers?

Mr Walton: I think that there are a lot of policy options or choices available to insurers as well as significant judgements and interpretations. I guess that applies more broadly through the standard, but particularly to transition as well. I have already mentioned a couple of the choices that are available.

For me, that range of choices and interpretations is likely to lead to a wide range of approaches being taken by insurers. That does not make it easy to compare results. Any time there are judgements or interpretations needed under IFRS 17, you are required to disclose what those judgements are. To some extent that will mitigate that point around comparability. I would raise the question of how effective that is going to be, given the quantity of disclosures that IFRS 17 requires.

When we talk about comparability and the range of approaches, we need to be careful about what we are comparing against. It is really easy to highlight areas where insurers might differ in their interpretations under IFRS 17, but insurers using different approaches to an accounting standard is definitely not a new thing. If you compare IFRS 17 with what we currently have under IFRS 4 , under IFRS 4, we have a huge range of approaches being followed and we do not have the consistency of approach by insurers across the globe.

If we are going to talk about whether there is an issue in terms of comparability, we do not always mean that we are comparing to current accounting. That is really what the discussion should be focused on.

Mr Yousuf: Picking on this angle of comparability that Rob (Walton) just noted, in terms of how results could be compared with those under current accounting, there are two ways of looking at the problem.

Either you say that IFRS 17 is a new regime entirely and therefore anything that we used to know about how we measured performance previously is no longer useful to be compared against; or you say that despite that we would like to put in place a transition strategy that actually addresses, or at least informs, what level of profits or what the shareholder equity position needs to look like compared to what we currently have.

In particular, the types of conclusions that insurers who are performing their impact assessments are reaching are that, in some cases, equity could take quite a large impact or profit profiles may no longer be what they used to expect. Therefore, one angle of comparability would be to ask whether there is a way that we could revisit the methodology, or look at some types of business combinations or other types of transactions whereby, if you do not like the answer that you are getting, you can somehow address the underlying problem that way.

The Moderator: The next topic is reinsurance. The latest version of the standard includes some new requirements for addressing the scenario where insurance contracts were written at a loss, but where the reinsurance of that business made a net gain. Why has the industry pushed for these changes? And do they hit the mark?

Mr L. S. Tan, F.F.A.: Maybe we can look at the sequence of events for this topic. Initially, in the 2019 exposure draft, for insurance contracts that at initial recognition were expected to be lossmaking, entities had to recognise the expected losses on the initial recognition of the underlying 
contract, but at the same time, the amendments required us to recognise any recoveries of those losses from the corresponding reinsurance held.

However, the problem was that it was quite a restricted range of scenarios where you could recognise the expected recoveries. That is, it was only applicable to very specific, proportionate reinsurance coverages. That is, I think, what you alluded to in terms of the insurance industry, looking into lobbying for changes to the way reinsurance was measured.

If we look at the narrower definition (when reading the 2019 amendments), one might say it only applies to very plain, vanilla quota share type arrangements. Things like surplus arrangements or excess of loss type reinsurance treaties would be excluded. For life insurance, I guess surplus type arrangements would not fit into that coverage.

The insurance industry lobbied the IASB to get a wider scope of eligibility for reinsurance treaties where you can recognise the expected recoveries to offset the underlying losses. From the IASB outreach activities, which resulted in a change to the proposed requirements.

Worth noting that the reason IASB restricted relief being available under non-proportionate contracts was because there was an initial view that this relief might be subject to interpretation by entities in terms of how to apply the recovery calculations to reinsurance treaties that were not proportionate coverages. The industry in turn responded by arguing that they would be deriving assumptions through contracts that have been written, so they would already have the assumptions that would be broadly needed to use in the reinsurance calculations. In effect, that meant they were not arbitrary assumptions. That shows this issue can be looked at from a much broader perspective.

This change then brings us to the question of what it means to the insurers in practice. One thing is that, potentially, it is a drag on the longer term performance. You get one-off relief upfront, but it does mean a drag on your longer term performance.

In the operations area, the standards are not prescriptive. There are questions that might arise in these areas. How do you actually calculate the loss recovery components? How do you amortise it? How do they interact with the loss components on the underlying contracts?

Another interesting point is that the standard talks about underlying contracts that are onerous, perhaps due to claims or high acquisition expenses - how does that interact with the reinsurance loss recovery?

The Moderator: Continuing with the reinsurance topic, how problematic is the issue of including future new business for reinsurance held? Is there a way we could avoid these challenges?

Mr Yousuf: One of the reasons we mentioned this particular point, and we address it in the paper, is the IASB insist that the inclusion of future new business is not a source of ongoing mismatches between the gross contract and the reinsurance help for it.

What we have done in the paper is we have tried to illustrate the narrow set of circumstances that need to be held for that to be the case, for IASB's claim to be true. What we think is that, in reality, most companies will have extremely different approaches in terms of how they allow for accounting estimates in relation to prior periods, for example. Therefore, the mismatches that the IASB claim should not arise do in fact end up arising.

So, what we try to cover in the paper is that even if we granted to the IASB that there is no mismatch, because the liability for remaining coverage on the gross side in respect of new business is offset by the asset for remaining coverage on the reinsurance side, the shape with which that liability or asset develops is problematic.

Regarding how you could address this, we mention in the paper tactical ways in which you could deal with inception dates, for example. 
Mrs Stansfield: I think that from a new business perspective, or future reinsurance treaty perspective, there are a couple of points to make. First, the issue arises because of the termination clauses within most reinsurance contracts. A lot have a 3-month notice period that the reinsurer or the life insurer has to give to stop ceding business to the reinsurer. That 3 months brings in the contract boundary for the new business.

A calendar 3 months will generally, if you can line up the dates, fit with the reporting period that an entity has. You have some flexibility here and also around the wording of the clauses. We have seen people investigating with reinsurers whether they can create some sort of wording that means that on the first day of that reinsurance treaty, the notice period will go up until the end of the current quarter and then after that, it will be 3 months. So, for 1 day, 1 month, you have a shorter notice period and then after that it goes up to 3 months.

If you can get that to tie up with the first day of a quarter, then you can make it work. Effectively, by the end of the quarter, you know what your new business is, so you are not dealing with an unknown.

The other point is around how long that notice period is. Three months may be convenient. However, some contracts may have a 90-day contract that works in general, but over time 90 days will move further and further apart from your quarter end. There may again be changes that you can make, so you change 90 days to 3 months. Commercially, it is probably not going to make a big difference but it may neaten things a little.

Transition is more difficult. Clearly, you cannot retrospectively change when your reinsurance contract started. You are possibly looking at whether there are materiality arguments that could be made. That will obviously be unique to each entity.

The Moderator: We will now move on to coverage units. This is a huge topic. There is a lot of good discussion of this within the paper. I have two questions. The first question is, what are the particular challenges in defining coverage units for life insurance?

Mr Walton: I think that it is such an important part of the standard because your coverage units are what that fundamentally drives the pattern of profit recognition for insurance under IFRS 17.

For such an important area of the standard, there is not a huge amount written in the standard. So insurers are considering the Transition Resource Group (TRG) guidance, and a range of examples for different scenarios are included there. The guidance is very clear that judgement is needed in a few areas.

In the amendments, the standards have brought in more, particularly on investment return service. They have deliberately not been prescriptive on how to define coverage units.

In some cases, it may be very clear. It may be quite simple to define what your coverage units are, particularly where you have examples that are quite aligned with those given by the TRG. In practice, many insurance products are more complex than those examples. We are seeing a lot of cases in practice where it is not straightforward.

I will now consider some examples where there is judgement. First, the quantity of benefits provided for insurance coverage. The TRG set out some principles around this, essentially revolving around the idea that this is the amount an entity is standing by ready to pay to a policyholder. Even with those principles, this is not always clear. We have seen different views in the industry about what the benefit to the policyholder actually is for a particular product. I know, for example, annuities have had a lot of debate about what the benefit is that the policyholder receives in a given period.

The next area I would say is the existence and definition of coverage units for investment return service. As I say, the amendments to the standard brought in more wording and added new content to an investment return service under the general model. They set out some criteria to follow as to whether an investment return service does exist, which helps. But there is, of course, some 
interpretation and judgement needed there in terms of the existence and the investment returns service. Even if you do conclude that there is one, defining coverage units for that service has been deliberately left as an area of judgement. The IASB are keen not to prescribe exactly how that should be set.

The next area is weighting the coverage units between different types of service. Many insurance products will have different types of insurance coverage. They might have benefits that are a regular income versus being a lump sum, for example. In those kinds of cases, it does not make sense to add coverage units together for very different types of benefits.

Again, the TRG were clear that some weighting between different types of service may be needed and judgement is required for that. That is not just different types of insurance coverage, but also a whole host of insurance products that will have combinations of insurance and investments or investment return service where judgement is going to be needed as to how you combine those. That really is a crucial area because it is saying "how much weighting do I want to give to these types of services?" "How much weighting is appropriate?" As I say, that will drive profit recognition around those types of service and we are really getting into what the nature of the contract is and the view of the insurer of the importance to the policyholder of those different services being provided.

The last area I will highlight, and I will not go into too much on this question, is the standard gives an accounting policy choice as to whether or not you discount coverage units - whether or not you allow for the time value of money. That is the last area that I would flag as an area of judgement in defining coverage units.

The Moderator: I will go to Brendon (Thorpe) to get his thoughts regarding the appropriateness of allowing for the time value of money in measuring the coverage.

Mr B. Thorpe: I understand from discussions in the working party that this is not really a material consideration in some markets, and it is just assumed that discounting will be allowed for.

But I think, coming from my perspective in South Africa, it is worthwhile to take a step back and note the drivers that can lead to materiality and the materiality of this assumption, and how they could potentially increase in the future.

In particular, you are looking at product features such as longer durations and contractual increases, and all of those things can increase materiality whether you allow for discounting or not in the coverage unit. Obviously, the most important consideration is the level of the discount rate. So, it is worth noting that in a prevailing low discount rate environment, which you have in certain markets at the moment, this may mean that it is not currently considered to be a major consideration.

However, given that this is likely to be specified in the next year's accounting policy, you will communicate your choice of whether you discount or do not discount your coverage unit. You are potentially not going to have a lot of opportunities to change that in the future.

I think that it is necessary to look at any decision you take now and consider how that is going to impact you now and in the future. What you want is for your decision to remain relevant and to ensure reasonable emergence of profits regardless of the discount rate environment.

So, I would argue that people should be considering currently that discount rates are low and so the impact is quite low, but what would it look like if interest rates were to return to pre-Brexit levels in the UK, for instance? In markets such as South Africa, we are exposed to high discount rates. In particular, we are exposed to the whole-of-life risk products and policies with benefit increases.

What we see as the materiality, or the difference, between allowing for the time value and not allowing for the time value of money, is extremely material, and is actually so vast that in some cases and in some product types neither of the approaches could actually be considered 
appropriate. That is not discounting the coverage unit or allowing for a nominal discounting of the coverage unit.

That is something that we are having to grapple with at the moment. What we are looking at is - and it is explored in the paper - potentially some intermediate approach. An example is a line for real discounting. You are discounting your coverage in real terms, which would potentially correctly capture the situation where the company is providing an unchanged service in real terms over time. For example, on inflation-linked benefits.

What we wanted to do in the paper was to highlight this to start a discussion. If the standard allows for these two extremes, as long as your method is justifiable and consistently applied across periods, potentially you would want to consider such an intermediate approach.

The Moderator: I think this makes us all remember that low-interest rates may not last forever and there are different environments all over the world.

We will now move on to with-profits. How does IFRS 17 compare with current accounting for with-profits?

Mrs N. Mirin, F.I.A.: I would probably call it a very different approach from what we currently have under IFRS 4 or Solvency II. One of the key differences, probably the most important to note, is the mutualisation requirements under IFRS 17, where companies would have to use a different accounting approach for some of the cash flows under with-profits groups of policies. They would need to ensure the cash flows generated by with-profits policies are included in groups of contracts and in the periods where they arise rather than included in the groups of contracts where they arise, but not where due to the pooled approach, they may eventually end up.

Here, insurers face challenges in translating the IFRS 17 requirements appropriately to the cash flow allocation for groups of contracts and, therefore, the CSM calculation itself for each respective group of with-profits contracts. Apportioning mutualised cash flows is a challenge. Up to now, with-profits valuation methodologies used the pooled management approach. Insurers need to think of how to adopt it for with-profits portfolios.

The key issue in getting the right balance in the methodology of the CSM calculation for withprofits contracts is how to satisfy the IFRS 17 requirements while still retaining the pooled withprofits nature of this product.

Another thing to note is that the link between with-profits policyholder owned funds and shareholder-owned funds would probably need to be considered again. Within the CSM projection, this ensures the share of with-profits funds is the key component of the CSM calculation. It is the key component of insurance income and the mechanism of sharing a proportion of withprofits business may need to be given additional thought to ensure that a stable and realistic projection of the insurer's share is derived.

The smoothness of future P\&L profit streams from these groups of products will depend on the stability of the initial projection. These two things would probably act to incentivise potential improvements in with-profits products and management to increase the insight clarity and perhaps operational simplicity.

These improvement ideas will apply to new business. In-force with-profits portfolios will still face challenges of aggregation and appropriate cash flow allocation for CSM calculation purposes.

In terms of external users of insurance reporting, the most noticeable difference to external users would be they expected more of a profit pattern from these with-profits products. The shape of projected profits is likely to be different due to the IFRS 17 requirements to release the CSM in line with services provided. In the UK, the common $90 \% / 10 \%$ case means a large amount of profits will be released at the end of the contract's life along with a terminal bonus.

Under IFRS 17, this expected profit stream will need to be projected into the future and the release of these profits will be smoothed over the years under the current unit of services provided 
calculation mechanism requirement. We will still see a little spike in profits upon terminal bonus payments. However, the largest part will be smoothed out and released, in this case perhaps early in the contract, which would result in a less volatile income projection from this with-profits group of policies.

Whether these changes are good or not good again depends on the way that insurers look at it.

Mrs Stansfield: The point that I wanted to bring out is probably a more specific difference for products with guaranteed annuity options (GAO). For those who have not been banging their heads against this wall for the last 12 months, this issue is to do with contracts that were issued perhaps 20 years ago or longer. They were with-profits pension saving contracts that had an option at retirement to take up an annuity product at guaranteed terms.

Under current accounting, most entities would generally treat those as two contracts so they would look at the with-profits contract and then, after vesting, if the option is taken up, they will set up a new annuity contract. That is how systems, models, and data are all set up.

Under IFRS 17, the interpretation that seems to be embedding is that they should be one single contract. You have the with-profits phase and the annuity phase within one single contract. That leads to quite a few challenges for entities.

First, much of this business is already on the books, so you are looking at calculating a transitional CSM. Because your inception date is the original inception date from when the original with-profits contract was taken up, which may be 20 years ago rather than in the last 5 years from the annuity. You, therefore, have to try to get back to that data from 20 plus years ago. Many entities will (a) have challenges with that data and (b) may not even be able to link the annuity that they have today to the original with-profits contracts. They may not even know whether that annuity contract came from a with-profits contract or not.

That is going to push a lot of the annuity business down a fair value approach because they just will not be able to do a retrospective approach. That will have potential commercial implications on the size of that CSM at transition.

Another point that is going to create a lot of challenges, and is still a little bit uncertain concerns the measurement model. Companies will have to assess which measurement model to use from the general measurement model and the Variable Fee Approach (VFA) for that single contract. They will have to determine whether both phases of that contract will go under the general measurement model or VFA.

The consensus is still emerging in terms of which side of the fence it will fall. Either way, there is no good option really. You either have the problem of trying to work out how to measure a withprofits contract on the general measurement model, which is going to lead you to probably P\&L volatility during the with-profits phase; or you are going to have to try to measure an annuity under the VFA measurement model, which again was not designed for that purpose and will end up with some volatility in the annuity phase. So, there are many challenges around that issue.

Miss K. Malde: Just to add more on the measurement model issue for with-profits business. A similar problem arises when the policy becomes paid up and no longer participates in the profits share, which it would if it were a premium paying in force contract. The policy has now moved to a paid-up option so the general measurement model approach might not be appropriate. But if the policyholder revives the contract it starts participating again so, as there is no choice to use different measurement models for different parts of the policy's life, it becomes essential to make the decision at policy inception as to whether a lot of policies are going to take up the paid-up option. And so it will be more like a guaranteed product for most of the policy's life and they might prefer to use the GMM rather than VFA. If few policies take up the option, it might be better to measure under the VFA. 
Another clarification where the standard introduces testing measured under VFA or GMM is that within one product two policies might fail the test because the guarantees are more important than the actuarial bonus declaration, so two policies might be measured under GMM and the larger part under VFA. Operationally, it is not easy to deal with two measurement models for the same portfolio or the same product. Entities will need to decide which approach to take. It will depend on whether the results are easier to explain and how it compares with the existing IFRS 4 reserves.

The Moderator: I think that will definitely have convinced everyone that IFRS 17 for with-profits business is going to be challenging. But this paper and thinking on this is helpful to us all. Before we move to the audience, we have just one last question for the group. We call it the "magic wand" question. If you had a magic wand and could change just one thing about IFRS 17, what would it be?

Mr Thorpe: Thanks. I think that if I had a magic wand I would probably change the locked in discount rate assumption for the CSM. I know that this has been a contentious issue and the IASB has had a lot of questions on this. It has been firmly decided not to revisit it. I think the reason for that is, aside from the inherent complexity, it introduces which really is a bald issue and quite easily resolved, having worked through a number of years of transition and, in particular, material change in the discount rate, you can see first-hand the volatility that the lack of consistency in the rates can introduce.

Aside from the obvious direct volatility, where you have the impact of changes in the discount rates not being offset through a change in the CSM, you can have an additional volatility being introduced through measuring changes in performing cash flows related to future surplus at the current discount rates in the balance sheets but at initial recognition rates to the CSM. That difference is required to be treated as an insurance finance income or expense reflected through profit and loss in accordance with paragraph 46.

So, the direct volatility due to changes in the discount rate is potentially less of a concern, as you can reduce it through an effective asset-liability matching or hedging strategy, but this additional volatility is not so easily addressed. To reduce it, you would maybe have to look at the use of disaggregation through other comprehensive income, which is an option available in the standard, but it does add complexity to the model. But none of this consideration would be necessary if there was consistency in the rates. That would be the thing that I would change.

Mrs Mirin: If I had a magic wand, I would probably make IFRS17 apply going forward rather than retrospectively. I think it would make life easier for designing accounting for a lot of business. In terms of in-force business, I would probably, again through the magic wand, have some sort of simplified transition approach plus transitional measures over 10 years or so, something similar to what we have for Solvency II in order to digest that change in terms of CSM introduction and impact on equity over time rather than from day 1.

Miss Malde: For me, what I would want to change with a magic wand would be to make withprofits simpler for insurers, maybe by introducing a simpler measurement model test or just having a separate approach, which is only specific to with-profits and not overlapping in the wider bracket of participating contracts.

Mrs Stansfield: I think that I would use my magic wand in a similar way to Kruti (Malde). That would be fixing specifically the GAO issues that I have spoken about, but more widely the other products and issues that are experiencing that same challenge where you have a change in the middle of a contract that would ideally lead to a change in the measurement model. 
For me, having the whole contract on a single measurement model leads to huge operational challenges for companies and it is also leading to accounts being less clear for users of accounts. So, for example, on the GAO issue, now we are going to have the potential situation where you have annuities that came from sales in the market or annuities that came from with-profits. Once they are annuities the company will treat them and manage them in exactly the same way. However, they may end up being accounted for completely different and therefore not comparable at all. That does not feel ideal for users.

Mr Yousuf: I guess I would say to get rid of the need to allow for future new business in the estimates for reinsurance held. You can understand why the IASB think that it does give information, but I cannot figure out how you use something that will undoubtedly change when you have not written the business that you were expecting in the first place. I would do away with that one.

The Moderator: The first question is on transition. Do we have a high-level market-wide view of the percentages of portfolios that are likely to transition by each of the three methods: the full retrospective, the modified and the fair value?

Mr Walton: I am not going to answer it with percentages of portfolios. I think what is more interesting is the trend since the standard was first published, or when the exposure draft first came out, around how people have viewed this as they have gone through the implementation journey.

What I have seen historically is a full retrospective approach. Originally, people thought a lot about the data and assumption availability and those kinds of issues and thought to themselves "that is going to give me a problem if I go back a certain number of years but this thing is doable for a certain amount of time".

I did not see a huge amount of support or active take-up when people first looked at the modified retrospective approach. I think fair value was probably seen as the easy option where full retrospective is impractical.

I have seen that thinking change over time. I think people are seeing the full retrospective method as increasingly more difficult than first thought. We are talking about a smaller number of years where that might be practical, particularly the point that I raised earlier around thinking in more detail around the use of hindsight and how you avoid that.

Where the modified approach might previously have been ignored in the past, I think it will be getting a bit more attention now because it offers a route to actually solve some of those issues on the full retrospective approach where it is impractical. If I take the risk adjustment aspect, for example, this is a common area where hindsight might be needed to calculate it retrospectively, but I think quite a few people are seeing the modification as quite useful.

Fair value, whereas originally it might have received a lot of support, I think people have now had the chance to go through some of the numbers. For some, it might work for them, but for a lot of people seeing the easy option is not enough if it does not work for you financially.

As I say, I am not giving percentages across the market of what is being used, but that is how I have seen the trends develop in those three areas.

The Moderator: The next question is: what are the lines of business that are likely to see the most impact or boost to equity from the transition from IFRS 4 ?

Mr Walton: For me it depends on a number of things. It depends on the maturity of the in-force business at the transition date. It depends on your pattern of profit recognition under your current accounting which, as you say, is not going to be the same around the world. And it depends on the transition approach used. 
If I perhaps oversimplify slightly and take the example in the UK of annuities and with-profits business - under current accounting, annuities have a relatively front-loaded profit recognition pattern where a lot of the profits are recognised upfront. With-profits business has a relatively back-ended profit recognition aligning with the declaration of terminal bonuses.

For either of those types of products, IFRS 17 has the effect of smoothing out the recognition of profits. I am oversimplifying slightly. What that basically means is seeing a hit to equity or annuity-type business versus, say, an increase in equity for with-profits business.

Although there is an oversimplification here, there are a lot of things to consider. I think that is the general concept I am looking at in the example in the UK.

Mr Yousuf: Possible examples you might have been alluding to, Rob (Walton), in terms of areas of consideration, ultimately the accounts are meant for the business as a whole. So, think of companies with both life and non-life business. You might have impacts on the life side that are being offset by impacts on the non-life side. Even though it looks interesting to consider a line of business in isolation, ultimately, the accounts overall give you a much different picture and the basis on which you probably ought to be looking at your business.

In terms of some minor technical details - again, as Rob (Walton) said, it depends on so many things. Other things that it could depend on are how much DAC you previously had and how does the implicit unwind, or run-off, of the new acquisition cash flows embedded in the CSM compared to that. Maybe you have been very prudent in your reserving under IFRS 4 and so the level of profits embedded in your margins or provisions for adverse deviation might suddenly go away quite significantly because the CSM at transition isn't high enough. That is a problem for some German companies, for example. It depends on where you are, who you are and what you have been doing in the past. The point that I would make is that there is no easy rule of thumb.

Mrs Mirin: May I make one quick note in addition to that which Rob (Walton) and Wijdan (Yousuf) said? The things they noted are absolutely key. There are some market or product leaders in terms of profit recognition. But I will touch on the profits that I expect to recognise in the future for a particular product or business line, whether it is for with-profits funds for future appropriation or whether it is the net present value of projected profits. I think companies would still target, when setting up methodologies for IFRS 17 valuation fulfilment cash flow projections as a traditional CSM, the same amount of profits to be recognised for the same product or business line. If it is different, I expect clear explanations to be set out as to why it is so different for the expected profits over the whole product life under current accounting.

The Moderator: Moving to another question, this one is about the onerous and non-classification comparability. I will read the question: recognition of onerous or not is mandatory at the time of the issuing of the policy. The same policy may be onerous for one company and may not be for another company due to different pricing assumptions. Will this give a fair comparison of the financials between companies?

Mrs Stansfield: A couple of points: first, when you are assessing whether a contract is onerous or not at the outset you should be looking at that on an IFRS 17 basis, which may or may not be the same as your pricing assumptions. But because it is IFRS 17 reporting assumptions they are obviously subject to audit.

I guess there is a role within that, justification to your auditors and within your auditor's review of those, to ensure that they are justifiable and they are realistic best estimate assumptions. Hopefully, that will help in getting consistency, but obviously, there will be slightly different views, and a best estimate assumption that is clearly applied requires a lot of judgement. 
The other point is going back to the point that Rob (Walton) made earlier about how the comparison between companies is not going to be perfect under IFRS 17 by any means, and there will be areas where comparison is challenging.

If you compare that to IFRS 4, we have the issue (of non-comparability between entities) at present and it is probably magnified at present. We already have the issue where different companies will set different levels of assumptions, different best estimate assumptions. As Wijdan (Yousuf) has just mentioned, on top of that, different companies are going to have different amounts of prudence in their assumptions as well.

Hopefully, under IFRS 17, while there are challenges with comparability they will probably be more comparable than they are at the moment.

Mr Walton: Whether a group of contracts is onerous or not, initial recognition is going to be driven by what your BEL is and your risk assessment. Best estimate assumptions - yes, it is the premium you are charging for that. It is the risk adjustment, the compensation that the company needs to take on that risk. It is supposed to be company specific.

We need to be a bit careful when we are talking about comparability as well. Whether it is onerous or not is supposed to be about whether it is onerous for that company. It is not a notional average market participant that we are talking about.

The Moderator: I have two questions about discounting or not discounting.

When you say that discounted or undiscounted does not provide a reasonable recognition pattern what is this reasonableness being measured against? Do you mean the existing recognition profiles?

Mr Thorpe: It is an interesting question. What profile should you be recognising your profits on? Some companies are probably going to start by wanting as little change from existing profit recognition profiles as they can get away with. From that point of view, a company may view the existing profile as the measure of reasonableness. If you look at it in terms of the standard, how should you be recognising service? That is when you really go to the coverage unit, and the theory behind the coverage unit and what it should represent.

You can look at the discussions that the TRG has given around coverage units. For a risk policy, for example, they suggest that for the quantity of benefits sum assured and coverage duration that something like the number of policies is used to account for the duration of the contract.

Earlier, when I was talking about the inflation-linked example, if your sum assured is increasing over time and the standard says you need to allow for those increases in your derivation of the coverage unit, are you providing an increasing service over time? If you believe you are providing an increasing service over time, then you should want your profit recognition profile to reflect that. That is why I say you need to give some consideration as to what a reasonable profile is. In real terms, you are not providing an increasing profile of service over time.

So, I think the definition of reasonableness is going to be quite company specific. Again, it is a complete area of judgement. You as a company are going to have to be comfortable with what you choose. If you choose to use a nominal discount and front-end load your profit stream, it means you are going to burn through your CSM and you are going to have a higher risk of policies turning onerous in the future. If you believe that is a reasonable way to represent your profit, you are going to have to answer those questions when it comes to that time.

As with everything in IFRS 17, it is difficult to define a concept. It is going to be company specific and it is going to be a judgement, but you are going to have to live by that decision. You must factor a lot of these considerations into your decision-making process.

The Moderator: I will move on to the next question on that topic. 
In a high-interest rate environment, some of the indications given as to whether insurers should decide to use discounted or not-discounted approaches are not sufficient. The gap between the recognition profile is too large. Can an insurer consider something in between?

Mr Thorpe: This is what I spoke about, and what is addressed in the paper deals exactly with this point. You have these factors coming together - high discount rate environment and product design features such as whole of life or increasing benefits - the difference between the two options is extreme. It is really, really extreme. We have shown an example of that in the paper. That is why we want to stimulate discussion as to whether an intermediate approach might be more appropriate.

Again, it comes down to what profile of recognition of profit of CSM is appropriate for this business. Neither of these two extremes may be considered extreme in practice. I would argue that some sort of intermediate approach is appropriate.

The standard talks specifically about whether you allow for discounting or not. It does not talk about whether that discounting is nominal or real. I definitely think that is one step that you can take in terms of the standard. Real discounting is an approach to an intermediate step. However, it is an interesting theoretical discussion that I think we perhaps need to start having as to the practical considerations in terms of what it is actually going to do to our profit emergence.

Providing your approach is applied consistently year by year, you are not going to introduce any volatility into your results. So, it is going to be consistent, you are going to hold yourself to that, but potentially some other type of middle ground approach could be allowable.

The first step there, which is relatively easy to argue in terms of the standard, is real discounting, because you are still allowing for discounting of coverage units. Whether we can take a step beyond that to something more intermediate and something that a company believes is reasonable, I think that is a theoretical discussion that still needs to be had and is something the auditors need to be comfortable with.

The Moderator: One more question: what are the direct reinsurance accounting mismatches that remain and are there any solutions that can simplify these operationally?

Mr Yousuf: I am going to answer this from one perspective. The fact that you cannot use the VFA for reinsurance held, even if you have reinsured underlying contracts that are VFA, is a model mismatch at a fundamental level.

Obviously, we know there is the risk mitigation option that could be applied. However, what we touch on in the paper is that even though this does get rid of a chunk of the mismatches that could arise, it does not eliminate them entirely, mainly because changes in discount rates taken through at that the same time as demographic assumption updates do not necessarily have the same impact on the GMM side. It is still an area where personally I disagree with the IASB.

Mr Tan: I would like to add some points on protection business. Generally, the way to get a better alignment depends on how you define your unit of accounts for your reinsurance contracts. If you can define it at a much more granular level, that will then ensure that the mismatch can be minimised. In terms of a 90-day or 3-month tranche as a unit of contract, which means that potentially you can get better alignment in terms of your discount rates and also your contract boundary projections.

This includes aspects such as whether or not you have multi-life benefits and whether you can consider structuring your treaties in a way that you can look at them as being more aligned with your underlying protection business. The treatment of addendums is also an issue - if you can look into whether you can potentially define a smaller unit of account. Effectively, I would advise 
to look through your books to see whether there are other areas of mismatch and look towards your definition of the unit of account.

\section{IFRS 17 CSM Working Party}

\section{Additional Q\&A}

Do you think the impact of COVID-19, and its possible impacts on companies' delivery timelines, might lead to IFRS 17 getting delayed further?

$O$ It is difficult to predict whether a further delay will be agreed or not. There have not been any indications from IASB about a further delay of the implementation deadline. The operational impact of COVID-19 on IFRS 17 projects varies from company to company. It may be the case that the insurers that have been affected least would have a strong desire to continue with the current implementation date. However, the insurers that are less ready would still want a further delay. We have to wait and see what happens in the future, but for the moment to proceed with the current deadlines.

O I have not heard any talk that may indicate anyone has an expectation of a further delay. I think the IASB are keen to get it done now so would be very resistant to a further delay; the publication of the final standard in June being an indication of their determination.

If IFRS17 leads to a smoothing of the emergence of accounting profits on with-profits business, how will companies manage the mismatch between the emergence of profit and emergence of cash flow from the with-profits fund?

Even currently, for many jurisdictions or industries, actual cash flows do not necessarily equate to the emergence of profit for reasons such as deferral of costs or smoothing requirements. From that perspective, IFRS 17 does not introduce any new complexity in terms of general cash flow management. However, the difference between transfers to shareholders and profits as per the IFRS 17 income statement will now act as an additional cap on the cash dividends that can be distributed to shareholders. So, within the shareholder equity from with-profits business, the entity will now have to track the cumulative balances of shareholder transfers and IFRS 17 profits released, and only the lower of the two can be used for dividends.

Does IFRS 17 effectively require an insurer to determine their BEL based on the premise that they need to "extinguish" their Bonus Stabilising Reserve (BSR) over the contract lifetime? If so, how are insurers practically approaching this?

O The BRS, or even the inherited estate, cannot remain unallocated and so IFRS 17 does require a methodology of allocating the cash flows from the BSR/estate to the groups of contracts to which they belong. We are not aware of the emergence of any clear strategies yet and there is no consensus as to how to practically approach this at present.

Do you think EFRAG's draft advice will have any implications on the requirements and timescales for the adoption of IFRS?

O There are two aspects here:

(1) From the UK perspective, the UK has its own Endorsement Board (EB) that will endorse IFRS 17 (EU endorsements after December 2020 are no longer binding). So, from that point of view, it is UK EB's advice rather than EFRAG's draft advice that is more likely to 
affect UK groups. The UK EB has begun the process of producing its own advice, but this is unlikely to be ready before summer 2021 .

(2) EFRAG advice has effectively signed off on everything except the annual cohorts under the mutualisation problem. It is not yet clear which way the UK EB will conclude on this point so this is one to watch out for. However, it seems safe to expect (for now) that, for companies that do not have with-profits business, UK's view will align with EFRAG draft advice so requirements and timescales should not be affected, and no further delays ought to be expected. 